\title{
Penilaian Efisiensi Bank dengan Data Envelopment Analysis pada 10 Bank Berperingkat Besar Di Indonesia
}

JMV. Mulyadi ${ }^{1}$

${ }^{1}$ Universitas Pancasila, Jl. Srengseng Sawah, Jagakarsa, Jakarta Selatan 12640

\section{N F O A R T I K E L}

\section{JEL Classification:}

O33

\section{Keywords:}

data envelopment analysis, input, output, production

approach, intermediation approach, revenue

approach and profit

approach.

\section{A $B$ B S $\quad \boldsymbol{T} R \boldsymbol{R} A \boldsymbol{C} T$}

Bank efficiency are important in the assessment of the health of banks. Data Envelopment Analysis is a model of efficiency assessment bank that is widely used because it provides a more detailed analysis of the results compared to financial ratios. Analysis carried out by the production approach, intermediation, revenues and profits. This study assesses the 10 major banks in Indonesia. The results showed that of the 10 large banks are still found inefficiencies. DEA resulted in a recommendation that development can be done bank to achieve optimum efficiency. Based on the recommendation expected the bank to maximize the desired profit through efficiency.

\begin{abstract}
A B S T R A K
Efisiensi bank merupakan hal penting dalam penilaian kesehatan bank. Data Envelopment Analysis adalah model penilaian efisiensi bank yang banyak digunakan karena memberikan hasil analisis yang lebih detil dibandingkan rasio keuangan. Analisi dilakukan dengan pendekatan produksi, intermediasi, pendapatan dan laba. Penelitian ini melakukan penilaian pada 10 bank besar di Indonesia. Hasil penelitian menujukkan bahwa dari 10 bank besar tersebut masih ditemukan inefisiensi. DEA menghasilkan rekomendasi pengembangan yang dapat dilakukan bank untuk mencapai efisiensi optimum. Berdasarkan rekomendasi tersebut diharapkan bank dapat memaksimumkan profit yang diinginkan melalui efisiensi.
\end{abstract}

\section{Pendahuluan}

Persaingan bisnis perbankan semakin ketat. Kondisi tersebut menuntut manajemen untuk dapat mengelola aktivitas operasional perbakan dengan cermat. Diversifikasi produk perbankan dengan menciptakan produk baru maupun dengan memodifikasi produk yang ada dengan dibarengi peningkatan teknologi merupakan tren perbankan saat ini termasuk kombinasi produk bank dengan asuransi, pelayanan wealth management, reksadana dan sebagainya. Salah satu upaya disisi lain yaitu bank-bank semakin melihat dan meningkatkan efisiensi dalam pengelolaan usahanya, berbagai rasio keuangan telah dikembangkan untuk mengukur efisiensi ini misalnya rasio BOPO yaitu rasio antara beban operasional dibandingkan dengan pendapatan operasional, cost eficiency ratio yang membandingkan jumlah dari beban personalia, beban umum dan administrasi dan beban operasional lain dibagi dengan net interest income dikalikan dengan jumlah pendapatan bunga dikurangi beban bunga provisi dan komisi, dan pendapatan operasional lain.

$$
\text { Data Envelopment Analysis }
$$


merupakan metode penilaian efisiensi yang mulai perkenalkan di Indonesia untuk menilai efisiensi perbankan. Harian Bisnis Indonesia bahkan sudah menggunakan DEA untuk memberikan award kepada bank-bank yang memperoleh peringkat efisiensi tertinggi. Lembaga Pengembangan perbankan Indonesia telah memperkenalkan penggunaan DEA untuk menilai efisiensi cabang Bank. DEA melihat efisiensi dari sisi yang lain yaitu seberapa efisien perusahaan menggunakan sumberdaya yang dimiliki untuk menghasilkan pendapatan.

Model DEA untuk suatu unit dapat diformulasikan ke dalam Linear Programing fraksional dengan menjadikan input dan output sebagai variabel keputusan. DEA menilai efisiensi dari unit sejenis yang mempunyai tujuan yang sama; unit dapat berarti bank, cabang, unit kerja atau produk. Efisiensi DEA diukur dengan menghubungkan antara total output dengan total input; sehingga penentuan input dan output ini menjadi penting dalam DEA. Input adalah semua sumber daya yang digunakan dalam operasional perusahaan sedangkan output adalah hasil yang diperoleh dari penggunaan sumberdaya. Semakin tinggi output perusahaan maka skor DEA akan semakin besar dan perusahaan semakin efisien. Sebaliknya semakin tinggi input maka perusahaan semakin kurang efisien dan akan tercermin dari rendahnya skor DEA. Contoh input untuk perbankan adalah jumlah tenaga kerja, jumlah aktiva tetap, jumlah modal, jumlah cabang, jumlah biaya operasional; sedangkan contoh output adalah jumlah kredit yang disalurkan, jumlah dana yang dihimpun, jumlah pendapatan operasional dan sebagainya.

DEA diperkenalkan pertama oleh Charnes, Cooper \& Rhodes 1978 dengan asumsi constant return to scale (CRS), kemudian 1984 diperkenalkan variable return to scale (VRS) oleh Banker, Charnes and Cooper.DEA memiliki karakter berbeda dengan konsep efisiensi pada umumnya. Pertama, efisiensi yang diukur bersifat teknis bukan ekonomis. Artinya, analisis DEA tidak membedakan nilai ekonomis dari tiap variabel seperti harga, berat, panjang, isi dan sebagainya, sehingga dimungkinkan suatu pola perhitungan kombinasi berbagai variabel dengan satuan yang berbeda-beda. Kedua, nilai efisiensi yang dihasilkan bersifat relatif atau hanya berlaku dalam lingkup sekumpulan unit yang diperbandingkan tersebut.

Beberapa penelitian yang menggunakan DEA untuk menilai efisiensi bank telah banyak digunakan banyak negara, misalnya temuan riset Oral, et al.(1992), Golany dan Storbeck (1999), Asish Saha dan Ravisankar (2000), dan Sathye (2001). Hal yang sama dilakukan di Indonesia antara lain oleh Sya'dullah (2002), Hadad, dkk (2003), Siswadi (2004) dan Mulyadi (2006). DEA dapat digunakan untuk meranking bank berdasarkan efisiensinya dan hasil analisis DEA juga konsisten dengan nilai saham bank-bank yang go-public dengan kata lain studi DEA konsisten dengan persepsi pasar atas bankbank tersebut. (Saha dan Ravisankar, 2000). DEA dapat digunakan sebagai pelengkap untuk menilai produktivitas dan profitablitas cabang selain menggunakan cara tradisional yaitu dengan rasio keuangan. Disamping itu DEA juga dapat digunakan oleh manajemen dalam melakukan realokasi sumber daya di antara cabang-cabang untuk mencapai efisiensi yang lebih tinggi (Muhittin Oral dkk,1992).

DEA dapat digunakan untuk menilai efisiensi cabang. Penelitiannya menyimpulkan bahwa pada kuartal ketiga 1993 terdapat 92 cabang bank yang mencapai efisiensi $100 \%$ dan hanya 5 cabang yang efisiensinya di bawah $70 \%$. Cabang yang memiliki outstanding kredit besar efisiensinya lebih besar. Dari hasil DEA juga dapat diperoleh reference set sebagai dasar cabangcabang melakukan benchmark. Ada perbedaan efisiensi cabang bank yang memiliki Personal Investment Centers (PIC) dengan yang tidak memiliki. Pada kuartal kedua 1992 cabang yang memiliki PIC efisiensinya lebih tinggi $(72,4 \%$ versus 44,9\%) (B. Golany dan Storbeck,1999).

Soteriou dan Stavrinides menggunakan DEA untuk menilai efisiensi cabang Penelitiannya menunjukkan bahwa dengan orientasi input diperoleh tingkat efisiensi cabang bervariasi antara 39\% sampai 100\%, dan efisiensi rata-rata $78,6 \%$. Dari DEA juga 
dapat diperoleh reference set sebagai benchmark cabang yang kurang efisien untuk melakukan penyesuaian atas variabel input-nya, dari sampel nampak bahwa cabang yang kurang efisien harus mengurangi input-nya. Dari model ini belum dapat digunakan untuk menentukan efisiensi cabang secara keseluruhan harus ditambah dengan aspek lainnya seperti profitablitas dan efisiensi operasional DEA dapat digunakan untuk menilai efisiensi cabang baik dari sisi operational efficiency, quality efficiency model maupun profitability efficiency. DEA mengindikasikan suatu cabang yang efisien sebagai benchmark dan seperangkat reference set bagi cabang-cabang yang akan melakukan perbaikan. Model ini juga memberikan acuan perbaikan variabel inputnya apakah dari biaya operasional (consumable resources) atau product-mix (revenue generating resources). Sebagai contoh dari hasil perhitungan DEA Juli - Desember 1994 untuk meningkatkan laba $12 \%$ dapat dicapai melalui pengurangan biaya $40 \%$ dan melakukan perbaikan productmix 60\% (Andreas Soteriou dan Zenios (1997).

DEA dapat digunakan untuk menilai efisiensi bank. Penelitiannya juga mengindikasikan bahwa sumber ketidak efisienan adalah lebih dari komponen teknikal dibanding alokatif. Jadi ketidak efisienan bank-bank di Australia lebih karena wasting of inputs (technical inefficiency) dibanding tidak tepat dalam pemilihan kombinasi inputs (allocative inefficiency). Bank-bank domestik lebih efisien dibanding bank-bank asing. Studinya juga mempunyai implikasi penting sebagai acuan bagi pemerintah dalam kebijakan mengenai deregulasi dan merger. Merger bank di Australia pada waktu itu mengakibatkan persaingan berkurang karena perbankan dikuasai oleh bank hasil merger (Milind Sathye, 2001).

DEA dapat digunakan untuk menilai efisiensi bank di Indonesia. Penelitiannya menyimpulkan bahwa dari lima bank pemerintah terdapat tiga bank yaitu Bank Rakyat Indonesia, Bank Ekspor Indonesia dan Bank Negara Indonesia memiliki tingkat efisiensi relatif lebih baik dibanding Bank Tabungan Negara dan Bank Mandiri. Tingkat efisiensi relatif yang dihasilkan sejalan dengan kinerja yaitu ROA ketiga bank pemerintah tersebut (masing-masing 2,08; 2,36; $1,70)$ lebih besar dibanding bank pemerintah yang lain (0,59 dan 0,77) (Makmun Sya'dullah, 2002). DEA dapat digunakan untuk menilai efisiensi bank di Indonesia. Informasi yang dihasilkan adalah bank-bank yang paling efisien selama periode 1996 sampai 2003 secara individual maupun kelompok bank (Bank Persero, Bank Swasta Nasional Devisa, Bank Swasta Nasional Non Devisa, Bank Asing Campuran dan Bank Pembangunan Daerah). Penelitiannya juga mengungkapkan bahwa bank-bank yang dimerger jika dianalisis secara individual (sample diambil tiga bank) efisiensinya semakin meningkat, tetapi pada saat bank-bank yang dimerger dianalisis per kelompok bank, secara umum memang ada peningkatan efisiensi namun ada beberapa bank yang sesudah dimerger efisiensinya semakin menurun (Muliaman Hadad dkk, 2003).

DEA dapat digunakan untuk pengukuran efisiensi relatif seluruh kantor cabang bank di Indonesia sehingga manajemen dapat menata kembali kondisi operasional bank agar dapat mencapai efisiensi relatif yang lebih baik. Disamping itu juga dapat memberikan gambaran target-target untuk perbaikan serta angka referensi dengan melakukan benchmarking pada cabang yang efisien. Dengan metode ini manajemen dapat menghemat waktu untuk lebih konsentrasi pada cabang-cabang yang inefisien saja (Erwinta Siswadi dan Wilson Arafat (2004). DEA dapat digunakan untuk meranking bankbank di Indonesia baik individual maupun per kelompok bank. Hasil analisis DEA secara umum konsisten dengan rasio LDR dan ROA. DEA juga dapat digunakan untuk menilai utilisasi sumberdaya perbankan. Skor DEA tidak dapat menjelaskan kegagalan bank di Indonesia pada 1997 dan 1999. DEA dapat juga untuk menilai efisiensi merger bank (Mulyadi, 2006). DEA digunakan untuk menilai pengaruh krisis ekonomi global terhadap produktivitas Bank di India. Hasilnya menunjukkan bahwa selama pra-krisis, peningkatan produktivitas sektor perbankan India dipengaruhi oleh inovasi teknologi dan efisiensi teknis mempengaruhi produktivitas 
dalam periode krisis dan pasca krisis. Hal ini mungkin karena efek dari krisis ekonomi bank akan berjuang untuk bertahan hidup dan sulit untuk berkonsentrasi pada inovasi teknologi baru (Madhanagopal et all, 2014).

\section{Telaah Teori dan Pengembangan Hipotesis}

DEA memiliki beberapa keunggulan dibandingkan dengan analisis rasio maupun regresi yaitu:

1. Analisis DEA didesain khusus untuk menilai efisiensi unit yang memiliki multi input dan multi output, yang biasanya sulit disiasati secara sempurna oleh teknik analisis lainnya seperti analisis rasio dan regresi.

2. Analisis rasio mengukur efisiensi dengan cara membandingkan nilai output dengan nilai input. Pada saat terjadi multi output dan multi input bisa terjadi banyak hasil perhitungan dan pertimbangan.

3. Analisis regresi menyusun suatu model dari tingkat output tertentu sebagai fungsi dari berbagai tingkat input tertentu, untuk membandingkan kemampuan unit lain dalam menghasilkan output. Unit yang efisien jika menghasilkan output yang lebih besar daripada nilai estimasi. Tetapi jika outputnya banyak maka analisis regresi juga tidak menghasilkan nilai yang memuaskan, karena satu persamaan regresi hanya menampung satu input, jika dilakukan penggabungan banyak input maka informasinya menjadi tidak rinci.

Analisis DEA mempunyai manfaat:

1. Scoring and ranking

Hasil perhitungan DEA dapat mengindikasikan unit yang paling efisien dan mana yang tidak efisien. Biasanya unit yang efisien skornya 100 sedangkan yang dibawah 100 kurang efisien.

2. Performance improvement

Output DEA juga memberikan informasi untuk unit yang tidak efisien agar menjadi efisien, berapa output yang harus ditingkatkan atau berapa input yang harus dikurangi, dan dalam faktor yang mana. Sekaligus diberikan target perbaikannya agar tercapai skor 100 (efisien).

\section{Benchmarking}

Hasil analisis DEA juga memberikan informasi untuk unit yang kurang efisien harus melakukan benchmark ke unit mana yang efisien dalam melakukan performance improvement agar menjadi efisien.

4. Resources allocation

Analisis DEA dapat memberiklan informasi tentang sumber daya apa saja yang diperlukan dalam operasi yang efisien dan memberi arah dalam melakukan ekspansi

5. Optimum operational scale

Analisis DEA dapat mengindikasikan seberapa skala operasional yang optimum dan berapa sumberdaya yang harus diinvestasikan pada skala optimum tersebut

6. Cross efficiency analysis

Analisis DEA dapat memberikan scenario bagaimana menghitung kinerja suatu unit individual dengan kondisi eksternal yang berbeda

Mekanisme perhitungan analisis DEA adalah sebagai berikut:

1. Skor efisiensi DEA dihitung dengan rasio antara total output tertimbang dengan total input tertimbangnya.

2. Setiap unit diasumsikan bebas menentukan bobot untuk setiap variabel input dan output yang ada asalkan memenuhi kondisi:

a. bobot tidak boleh negatif

b. bobot harus bersifat universal atau tidak menghasilkan indikator efisiensi yang diatas normal atau lebih besar dari 1 bilamana dipakai unit yang lainnya.

3. Dalam mencapai tingkat efisiensi yang maksimal maka setiap unit cenderung memiliki pola untuk menetapkan bobot yang tinggi untuk input yang penggunaannya sedikit, dan output yang banyak dihasilkan 


\section{Metode}

Penelitian ini merupakan riset kualitatif. Obyek penelitian adalah 10 bank besar di Indonesia. Pengolahan nilai efisiensi dilakukan dengan bantuan software Banxia Frontier Analyst Versi 4. Data yang digunakan adalah data perbankan yang berasal dari laporan keuangan bank yang diterbitkan di www.bi.go.id. Pengukuran dilakukan dengan perumusan input output dapat menggunakan pendekatan sebagai berikut :

\section{Production approach}

Dalam pendekatan ini dianalisis peran bank sebagai produsen jasa keuangan sehingga yang dimasukkan sebagai output adalah berbagai bentuk kredit, dana dan jasa lainnya sedangkan inputnya adalah modal, tenaga kerja, aktiva tetap, dan biaya operasional

\section{Intermediation approach}

Dalam pendekatan ini dianalisis peran bank sebagai lembaga perantara dari unit surplus dana ke pengguna sehingga yang dimasukkan sebagai input adalah dana, capital, labour dan biaya operasional sedang outputnya adalah kredit

\section{Assets approach}

Dalam pendekatan ini dianalisis peran bank dalam menghasilkan asset produktif jadi kelompok input outputnya seperti intermediation approach tetapi outputnya ditambah securities atau earning assets

\section{Profit approach}

Dalam pendekatan ini dianalisis peran bank dalam menghasilkan laba jadi outputnya profit sedangkan inputnya dana, modal dan tenaga kerja

Input data dan output yang dihasilkan terangkum pada Tabel 1.

\section{Tabel 1. Input dan Output Data Envelopment Analysis}

\begin{tabular}{|c|c|}
\hline INPUT & OUTPUT \\
\hline $\begin{array}{l}\text { - } \text { Beban bunga, beban provisi dan komisi, } \\
\text { - } \text { Beban personalia, beban umum dan administrasi, } \\
\text { beban penurunan nilai surat berharga, beban pro- } \\
\text { mosi, beban operasional lainnya, } \\
\text { - } \\
\text { Aktiva tetap (neto), } \\
\text { - } \\
\text { Ekuitas }\end{array}$ & $\begin{array}{l}\text { Ada } 3 \text { alternatif: } \\
\text { - Kredit yang diberikan (neto) saja atau } \\
\text { - DPK: Giro, tabungan, deposito saja atau } \\
- \text { Kredit dan DPK }\end{array}$ \\
\hline $\begin{array}{l}\text { Intermediation approach: } \\
\quad-\text { Giro, tabungan dan deposito }\end{array}$ & - Kredit yang diberikan \\
\hline $\begin{array}{l}\text { Revenue approach: } \\
\text { - Beban bunga, beban provisi dan komisi, } \\
\text { - Beban personalia, beban umum dan administrasi, } \\
\text { beban penurunan nilai surat berharga, beban pro- } \\
\text { mosi, beban operasional lainnya, } \\
\text { - } \text { Total aset, } \\
\text { - Ekuitas, } \\
\text { - Giro, tabungan dan deposito }\end{array}$ & $\begin{array}{l}\text { - Pendapatan bunga } \\
\text { - } \quad \text { Pendapatan provisi dan komisi } \\
\text { - } \quad \text { Pendapatan operasional lain }\end{array}$ \\
\hline $\begin{array}{l}\text { Profit approach: } \\
\text { - Beban bunga, beban provisi dan komisi, } \\
\text { - Beban personalia, beban umum dan administrasi, } \\
\text { beban penurunan nilai surat berharga, beban pro- } \\
\text { mosi, beban operasional lainnya, }\end{array}$ & $\begin{array}{ll}\text { - } & \text { Pendapatan bunga } \\
\text { - } & \text { Pendapatan provisi dan komisi } \\
\text { - } & \text { Pendapatan operasional lain }\end{array}$ \\
\hline
\end{tabular}




\section{Hasil Penelitian dan Pembahasan}

Analisis hasil pada penelitian ini mencakup production approach kredit, dana, kredit dan dana, intermediation approach, revenue approach, dan profit approach. Analisis DEA didesain khusus untuk menilai efisiensi unit yang memiliki multi input dan multi output, yang biasanya sulit disiasati secara sempurna oleh teknik analisis lainnya seperti analisis rasio dan regresi.

Analisis rasio mengukur efisiensi dengan cara membandingkan nilai output dengan nilai input. Pada saat terjadi multi output dan multi input bisa terjadi banyak hasil perhitungan dan pertimbangan. Analisis regresi menyusun suatu model dari tingkat output tertentu sebagai fungsi dari berbagai tingkat input tertentu, untuk membandingkan kemampuan unit lain dalam menghasilkan output. Unit yang efisien jika menghasilkan output yang lebih besar daripada nilai estimasi. Tetapi jika outputnya banyak maka analisis regresi juga tidak menghasilkan nilai yang memuaskan, karena satu persamaan regresi hanya menampung satu input, jika dilakukan penggabungan banyak input maka informasinya menjadi tidak rinci. Rincian hasil untuk masingmasing pendekatan adalah sebagai berikut.

\section{Production Approach - Kredit}

Production approach merupakan pende- katan pengukuran efisiensi dengan input beban bunga, beban provisidan komisi, beban personalia, beban umum dan administrasi, beban penurunan nilai surat berharga, beban promosi, beban operasional lainnya, aktiva neto, dan ekuitas. Alternatif outputnya berupa kredit, dana, dan atau keduanya. Berikut adalah hasil pengolahan dengan pendekatan produksi tersebut.

Analisis pada penelitian ini dilakukan tahun 2011 sampai dengan tahun 2014. Khusus tahun 2014 dilakukan analisis pengembangna potensial yang dapat dilakukan berdasarkan hasil analisis DEA. Analisis ini digunakan untuk menilai kemampuan bank dalam menyalurkan kredit. Bank yang memeroleh nilai 100\% berarti efisien sedangkan yang dibawah $100 \%$ berarti tidak efisien. Berdasarkan Gambar tersebut berarti Bank BNI dan Bank Danamon tidak efisien jika dibandingkan dengan bank lain per 31 Desember 2014. Software DEA ini memberikan solusi apa yang harus dilakukan agar Bank tersebut efisien atau agar mencapai nilai $100 \%$. Berikut adalah potential improvement yang dapat dilakukan bank tersebut agar efisien. Dalam software ini ada 2 pilihan yaitu meminimalkan input atau memaksimalkan output. Berikut adalah contoh potential improvement untuk Bank BNI dan Bank Danamon.

Tabel 2. Hasil DEA Production Approach-Kredit

\begin{tabular}{lrrrr}
\hline NAMA BANK & \multicolumn{1}{l}{$\mathbf{2 0 1 1}$} & \multicolumn{1}{l}{$\mathbf{2 0 1 2}$} & \multicolumn{1}{l}{$\mathbf{2 0 1 3}$} & \multicolumn{1}{l}{$\mathbf{2 0 1 4}$} \\
\hline BCA & $100.00 \%$ & $100.00 \%$ & $100.00 \%$ & $100.00 \%$ \\
BII & $100.00 \%$ & $100.00 \%$ & $100.00 \%$ & $100.00 \%$ \\
BNI & $92.50 \%$ & $93.10 \%$ & $97.20 \%$ & $97.10 \%$ \\
BRI & $100.00 \%$ & $100.00 \%$ & $100.00 \%$ & $100.00 \%$ \\
BTN & $100.00 \%$ & $100.00 \%$ & $100.00 \%$ & $100.00 \%$ \\
Danamon & $80.80 \%$ & $100.00 \%$ & $75.90 \%$ & $83.10 \%$ \\
Niaga & $100.00 \%$ & $100.00 \%$ & $96.90 \%$ & $100.00 \%$ \\
Panin & $100.00 \%$ & $100.00 \%$ & $100.00 \%$ & $100.00 \%$ \\
Permata & $100.00 \%$ & $100.00 \%$ & $100.00 \%$ & $100.00 \%$ \\
Mandiri & $100.00 \%$ & $100.00 \%$ & $100.00 \%$ & $100.00 \%$ \\
\hline
\end{tabular}



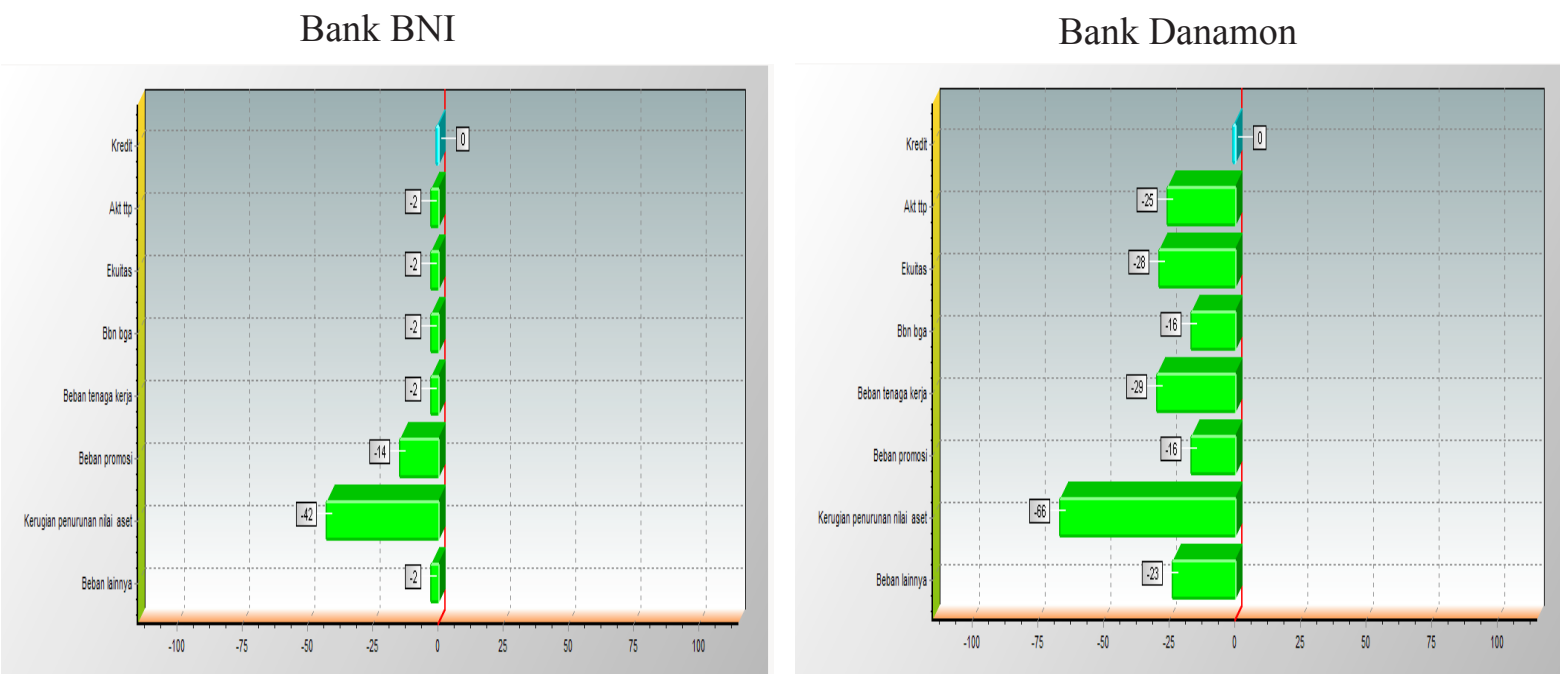

Gambar 1: Potential Improvement-Meminimalkan Input

Berdasarkan Gambar 1 Bank BNI dapat meningkatkan efisiensinya dengan cara mengurangi biaya kerugian penurunan nilai asetnya $42 \%$, biaya promosinya dikurangi $14 \%$ dan biaya-biaya lainnya dikurangi $2 \%$. Bank danamon dapat mencapai efisien atau skor efisiensi 100 jika aktiva tetap dikurangi $25 \%$, ekuitas berkurang $28 \%$, beban bunga berkurang $16 \%$, beban tenaga kerja berkurang $29 \%$, beban promosi berkurang $16 \%$, kerugian penurunan nilai asset berkurang $66 \%$ dan beban lainnya berkurang $23 \%$.

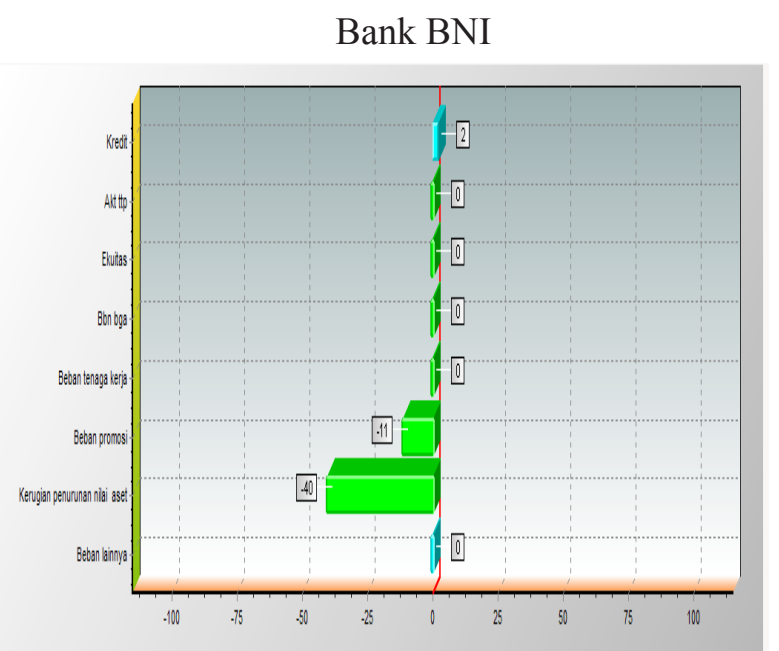

efisiensi 100\% maka Bank BNI dapat melakukan peningkatan kredit $2 \%$ dan penurunan biaya promosi $11 \%$ serta penurunan biaya kerugian penurunan nilai asset $40 \%$. Jika peningkatan efisiensi dilakukan dengan memaksimumkan output agar nilai efisiensi menjadi 100\% maka Bank Danamon dapat melakukan peningkatan kredit $20 \%$, penurunan aktiva tetap $10 \%$, penurunan ekuitas $14 \%$, penurunan beban tenaga kerja $15 \%$, penurunan kerugian penurunan nilai asset $59 \%$ dan penurunan beban lainnya $8 \%$.

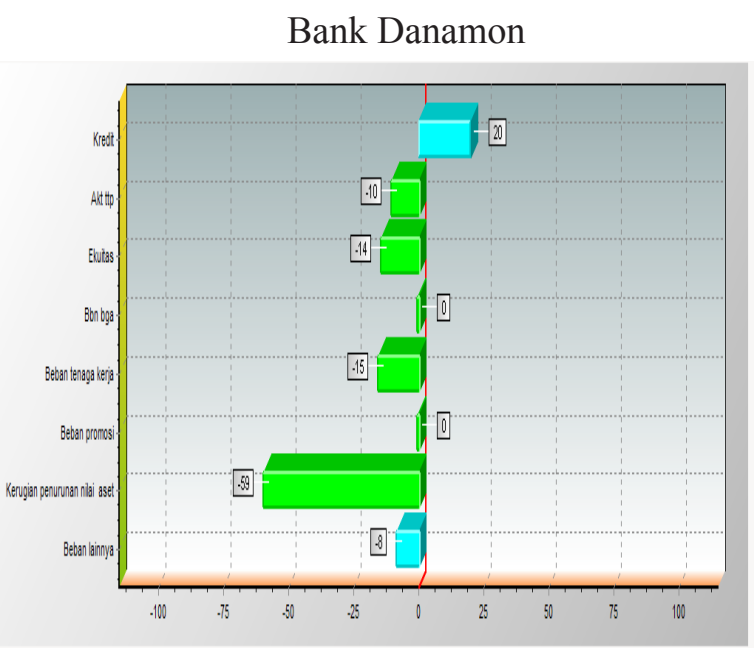

Gambar 2: Potential Improvement-Memaksimumkan Output

Jika peningkatan efisiensi dilakukan dengan memaksimumkan output agar nilai

\section{Production Approach-Dana}

Hasil lain yang direkomendasikan oleh pendekatan produksi adalah output dana. Tabel 
3 adalah hasil pengujian selama tahun 20112014. Berdasarkan hasil tersebut Bank Danamon memerlukan pengembangan pada tahun 2011, 2013, dan 2014.

Production approach ini digunakan untuk menilai kemampuan bank dalam menghimpun dana masyarakat dalam bentuk giro, tabungan dan deposito. Berdasarkan Gambar 3, Bank Danamon dapat mencapai efisiensi 100\% dengan meningkatkan tabungan $45 \%$, menurunkan input masing-masing sebesar: aktiva tetap $11 \%$, ekuitas $26 \%$, beban bunga $11 \%$, beban tenaga kerja $39 \%$, beban promosi $11 \%$, kerugian penurunan nilai asset $66 \%$ dan beban lainnya $22 \%$.

\section{Production Approach-Kredit dan Dana}

Hasil lain yang direkomendasikan oleh pendekatan produksi adalah output dana. Tabel 4 adalah hasil pengujian selama tahun 20112014. Berdasarkan hasil tersebut Bank Danamon memerlukan pengembangan pada tahun 2011, 2013, dan 2014.

Pendekatan Production approach ini digunakan untuk menilai kemampuan bank menyalurkan kredit dan menghimpun dana masyarakat. Dengan pendekatan ini kembali Bank Danamon tidak efisien dengan nilai $88,8 \%$. Jika Bank Danamon ingin meningkatkan efisiensinya

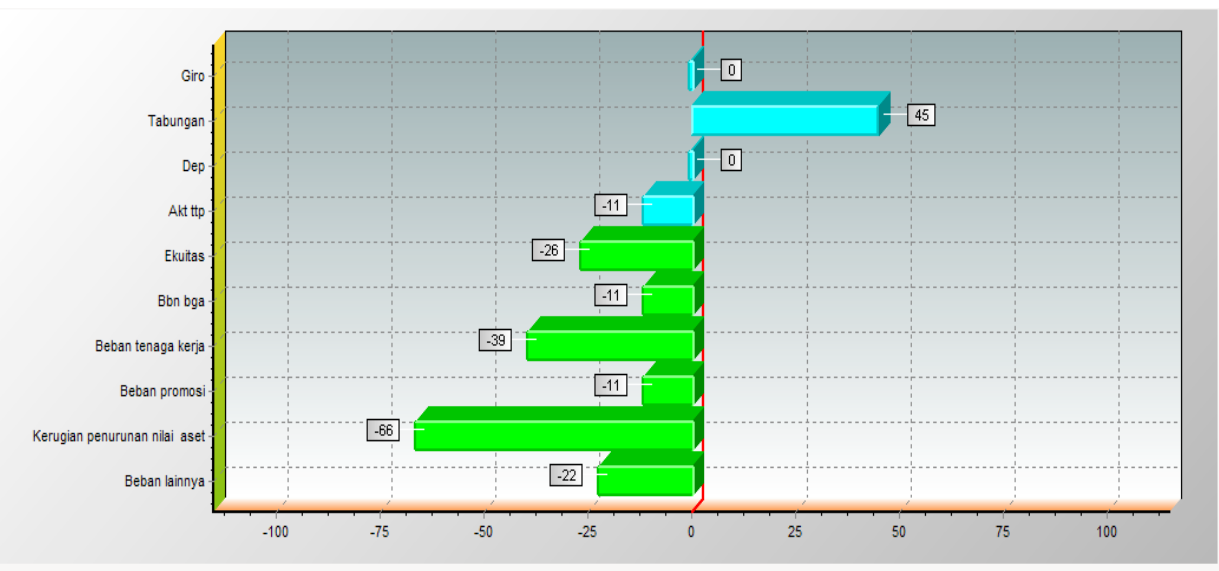

Gambar 3: Potential Improvement Bank Danamon - minimize input

Tabel 3. Hasil DEA Production Approach-Dana

\begin{tabular}{|c|c|c|c|c|}
\hline NAMA BANK & 2011 & 2012 & 2013 & 2014 \\
\hline BCA & $100 \%$ & $100 \%$ & $100 \%$ & $100 \%$ \\
\hline BII & $100 \%$ & $100 \%$ & $100 \%$ & $100 \%$ \\
\hline BRI & $100 \%$ & $100 \%$ & $100 \%$ & $100 \%$ \\
\hline BTN & $100 \%$ & $100 \%$ & $100 \%$ & $100 \%$ \\
\hline Danamon & $88.20 \%$ & $100 \%$ & $88.90 \%$ & $88.80 \%$ \\
\hline Niaga & $100 \%$ & $100 \%$ & $100 \%$ & $100 \%$ \\
\hline Panin & $100 \%$ & $100 \%$ & $100 \%$ & $100 \%$ \\
\hline Permata & $100 \%$ & $100 \%$ & $100 \%$ & $100 \%$ \\
\hline Mandiri & $100 \%$ & $100 \%$ & $100 \%$ & $100 \%$ \\
\hline
\end{tabular}


sehingga menjadi 100\% maka harus meningkatkan kredit 3\%, meningkatkan tabungan $45 \%$, menurunkan aktiva tetap $11 \%$, menurunkan ekuitas 26\%, menurunkan beban bunga 11\%, menurunkan beban tenaga kerja 39\%, beban promosi $11 \%$, menurunkan kerugian penurunan nilai asset $66 \%$ dan menurunkan beban lainnya $22 \%$. beban lainnya $12 \%$.

\section{Intermediation Approach}

Berdasarkan pendekatan penilaian intermediasi, diperoleh informasi bahwa pada

Tabel 4. Hasil DEA Production Approach-Kredit dan Dana

\begin{tabular}{lllll}
\hline NAMA BANK & $\mathbf{2 0 1 1}$ & $\mathbf{2 0 1 2}$ & $\mathbf{2 0 1 3}$ & $\mathbf{2 0 1 4}$ \\
\hline BCA & $100 \%$ & $100 \%$ & $100 \%$ & $100 \%$ \\
BII & $100 \%$ & $100 \%$ & $100 \%$ & $100 \%$ \\
BRI & $100 \%$ & $100 \%$ & $100 \%$ & $100 \%$ \\
BTN & $100 \%$ & $100 \%$ & $100 \%$ & $100 \%$ \\
Danamon & $88.20 \%$ & $100 \%$ & $88.90 \%$ & $88.80 \%$ \\
Niaga & $100 \%$ & $100 \%$ & $100 \%$ & $100 \%$ \\
Panin & $100 \%$ & $100 \%$ & $100 \%$ & $100 \%$ \\
Permata & $100 \%$ & $100 \%$ & $100 \%$ & $100 \%$ \\
Mandiri & $100 \%$ & $100 \%$ & $100 \%$ & $100 \%$ \\
\hline
\end{tabular}
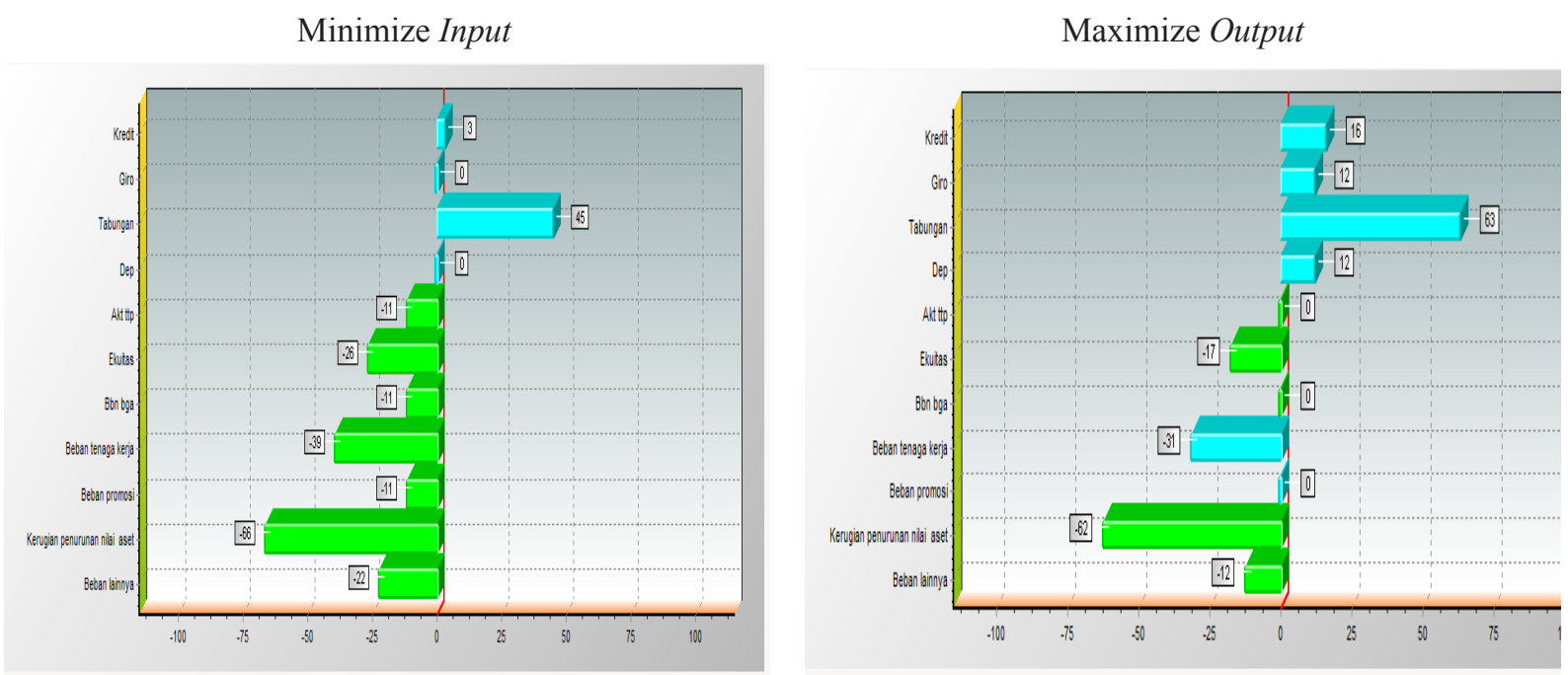

Gambar 4 : Potential Improvement Bank Danamon

Bank Danamon dapat mencapai efisiensi $100 \%$ dengan cara meningkatkan kredit $16 \%$, meningkatkan giro $12 \%$, meningkatkan tabungan $63 \%$, meningkatkan deposito $12 \%$ dan menurunkan ekuitas $17 \%$ menurunkan beban tenaga kerja 31\%, menurunkan kerugian penurunan nilai asset $62 \%$ dan menurunkan tahun 2014 Bank BRI, Bank Danamon, Bank Niaga, dan Bank mandiri. Tabel 5 adalah rangkuman hasil penilaian tahun 2011-2014. 
Tabel 5. Hasil DEA Intermediation Approach

\begin{tabular}{lrrrr}
\hline \multicolumn{1}{c}{ NAMA BANK } & \multicolumn{1}{l}{$\mathbf{2 0 1 1}$} & $\mathbf{2 0 1 2}$ & $\mathbf{2 0 1 3}$ & \multicolumn{1}{c}{$\mathbf{2 0 1 4}$} \\
\hline BCA & $100.00 \%$ & $100.00 \%$ & $100.00 \%$ & $100.00 \%$ \\
BII & $91.60 \%$ & $100.00 \%$ & $100.00 \%$ & $100.00 \%$ \\
BNI & $91.70 \%$ & $100.00 \%$ & $100.00 \%$ & $100.00 \%$ \\
BRI & $96.00 \%$ & $88.90 \%$ & $97.90 \%$ & $88.40 \%$ \\
BTN & $100.00 \%$ & $100.00 \%$ & $100.00 \%$ & $100.00 \%$ \\
Danamon & $100.00 \%$ & $100.00 \%$ & $100.00 \%$ & $93.40 \%$ \\
Niaga & $100.00 \%$ & $100.00 \%$ & $97.40 \%$ & $97.20 \%$ \\
Panin & $97.90 \%$ & $100.00 \%$ & $100.00 \%$ & $100.00 \%$ \\
Permata & $96.10 \%$ & $97.90 \%$ & $100.00 \%$ & $100.00 \%$ \\
Mandiri & $89.10 \%$ & 96.80 & $96.60 \%$ & 90.90 \\
\hline
\end{tabular}

Intermediation approach digunakan untuk menilai kemampuan bank dalam menyalurkan kredit dari dana yang dihimpun. Pendekatan ini menggunakan input berupa giro, tabungan dan deposito. Output pendekatan ini adalah kredit. Hasil penilaian efisiensi dengan menggunakan pendekatan intermediasi menunjukkan bahwa dari 10 bank ada 4 bank yang tidak efisien (yang nilai efisiensinya $<100 \%$ ). Berdasarkan hasil tersebut, yang perlu melakukan pengembangan adalah Bank Rakyat Indonesia (BRI),

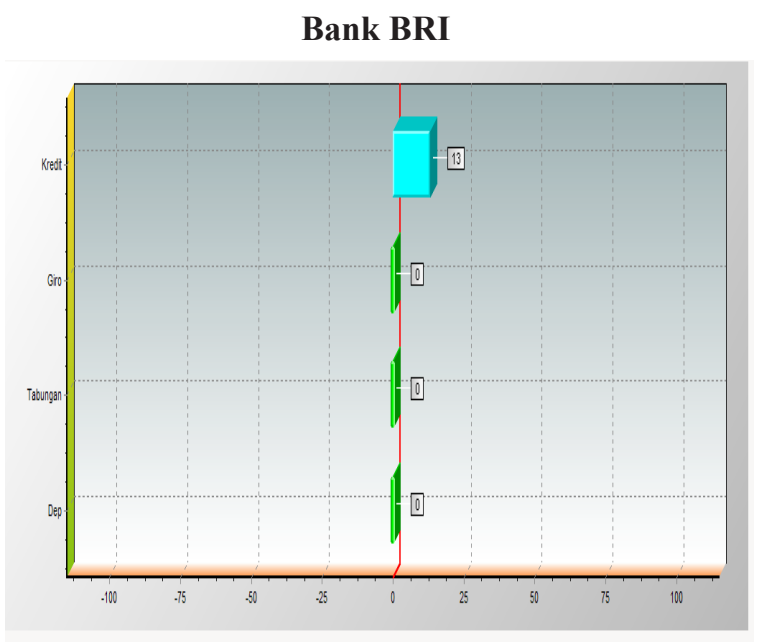

Bank Danamon, Bank Niaga, BNI dan Bank Mandiri. Untuk dapat mencapai efisiensi 100\% maka bank-bank tersebut dapat melakukan memaksimalkan output. Bank BRI perlu meningkatkan kredit 13\% agar tercapai nilai efisiensi 100\%. Bank Danamon akan mencapai nilai efisiensi $100 \%$ jika dapat meningkatkan kredit 7\%. Bank Niaga akan mencapai nilai efisiensi $100 \%$ jika dapat meningkatkan kredit $2 \%$ dan menurunkan dana 6\%. Bank Mandiri akan mencapai nilai efisiensi $100 \%$ jika dapat meningkatkan kredit $10 \%$.

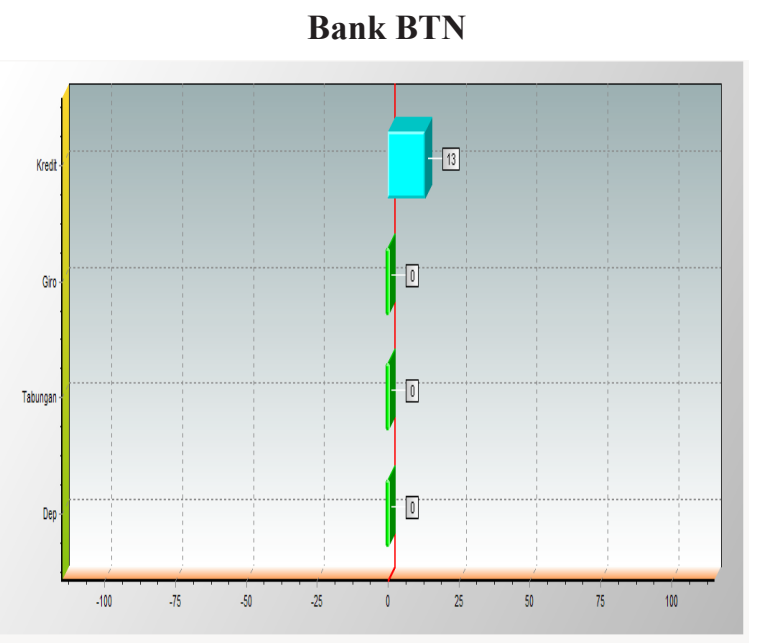



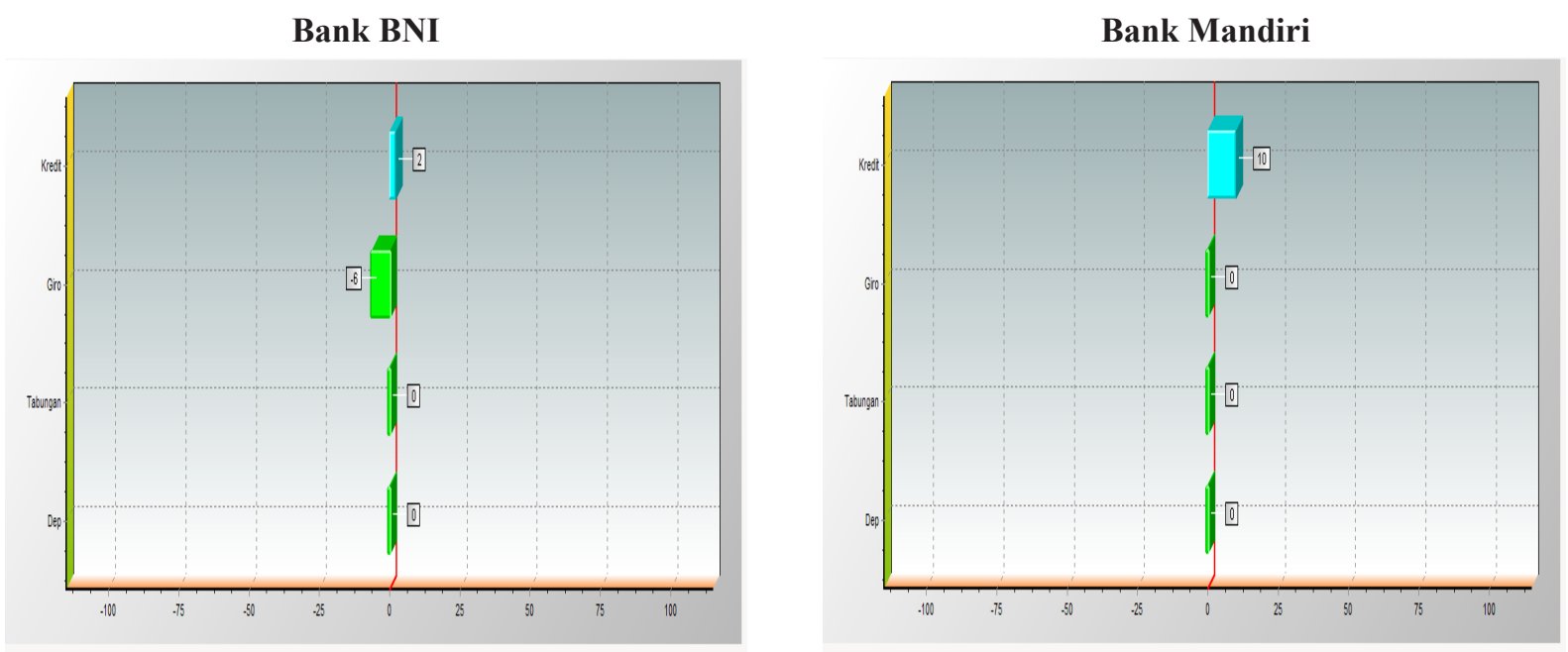

Gambar 5: Rekomendasi hasil DEA pendekatan intermediasi

\section{Revenue Approach}

Revenue approach digunakan untuk menilai kemampuan bank menggunakan sumberdaya untuk menghasilkan pendapatan operasional. Dengan menggunakan pendekatan revenue seluruh bank efisien karena memeroleh nilai $100 \%$.

\section{Hasil DEA Revenue Approach}

Tabel 6. Hasil DEA Revenue Approach

\begin{tabular}{lrrrr}
\hline NAMA & \multirow{2}{*}{ B11 } & $\mathbf{2 0 1 2}$ & $\mathbf{2 0 1 3}$ & $\mathbf{2 0 1 4}$ \\
\hline BCA & $100.00 \%$ & $100.00 \%$ & $100.00 \%$ & $100.00 \%$ \\
BII & $100.00 \%$ & $100.00 \%$ & $100.00 \%$ & $100.00 \%$ \\
BNI & $96.30 \%$ & $92.10 \%$ & $100.00 \%$ & $100.00 \%$ \\
BRI & $100.00 \%$ & $100.00 \%$ & $100.00 \%$ & $100.00 \%$ \\
BTN & $100.00 \%$ & $100.00 \%$ & $100.00 \%$ & $100.00 \%$ \\
Danamon & $100.00 \%$ & $100.00 \%$ & $100.00 \%$ & $100.00 \%$ \\
Niaga & $100.00 \%$ & $100.00 \%$ & $100.00 \%$ & $100.00 \%$ \\
Panin & $100.00 \%$ & $100.00 \%$ & $100.00 \%$ & $100.00 \%$ \\
Permata & $100.00 \%$ & $100.00 \%$ & $100.00 \%$ & $100.00 \%$ \\
Mandiri & $100.00 \%$ & $100.00 \%$ & $100.00 \%$ & $100.00 \%$ \\
\hline
\end{tabular}

\section{Profit Approach}

Berdasarkan pendekatan laba, hasil uji efisiensitahun2011-2014 sebagaimanaterangkum dalam Tabel 7. Pada tahun 2014 tampak bahwa Bank Internasional Indonesia dan Bank Niaga mendapatkan sinyal untuk melakukan efisiensi karena nilainya kurang dari 100\%.
Tabel 7. Hasil DEA Profit Approach

\begin{tabular}{lrrrr}
\hline NAMA & $\mathbf{2 0 1 1}$ & $\mathbf{2 0 1 2}$ & $\mathbf{2 0 1 3}$ & $\mathbf{2 0 1 4}$ \\
BANK & & & & \\
\hline BCA & $100.00 \%$ & $100.00 \%$ & $100.00 \%$ & $100.00 \%$ \\
BII & $100.00 \%$ & $100.00 \%$ & $100.00 \%$ & $100.00 \%$ \\
BNI & $96.30 \%$ & $92.10 \%$ & $95.70 \%$ & $100.00 \%$ \\
BRI & $100.00 \%$ & $100.00 \%$ & $100.00 \%$ & $100.00 \%$ \\
BTN & $100.00 \%$ & $100.00 \%$ & $100.00 \%$ & $100.00 \%$ \\
Danamon & $100.00 \%$ & $100.00 \%$ & $100.00 \%$ & $100.00 \%$ \\
Niaga & $100.00 \%$ & $100.00 \%$ & $99.90 \%$ & $96.70 \%$ \\
Panin & $100.00 \%$ & $100.00 \%$ & $100.00 \%$ & $100.00 \%$ \\
Permata & $100.00 \%$ & $82.90 \%$ & $100.00 \%$ & $100.00 \%$ \\
Mandiri & $100.00 \%$ & $100.00 \%$ & $100.00 \%$ & $100.00 \%$ \\
\hline
\end{tabular}

Profit approach digunakan untuk menilai kemampuan bank untuk menghasilkan pendapatan operasional. Dengan pendekatan ini ada dua bank yang tidak efisien yaitu Bank BII dan Bank Niaga. Bank BII dapat meningkatkan efisiensinya dengan cara meningkatkan pendapatan operasional lain 7\%, menurunkan beban bunga, beban tenaga kerja, beban promosi, dan beban lainnya masing-masing sebesar 9\% dan kerugian penurunan nilai asset diturunkan sebesar $61 \%$. Dengan maximize output Bank BII dapat meningkatkan efisiensinya dengan cara meningkatkan pendapatan bunga $10 \%$, pendapatan operasional lain 18\%, menurunkan kerugian penurunan nilai asset diturunkan sebesar $57 \%$. 

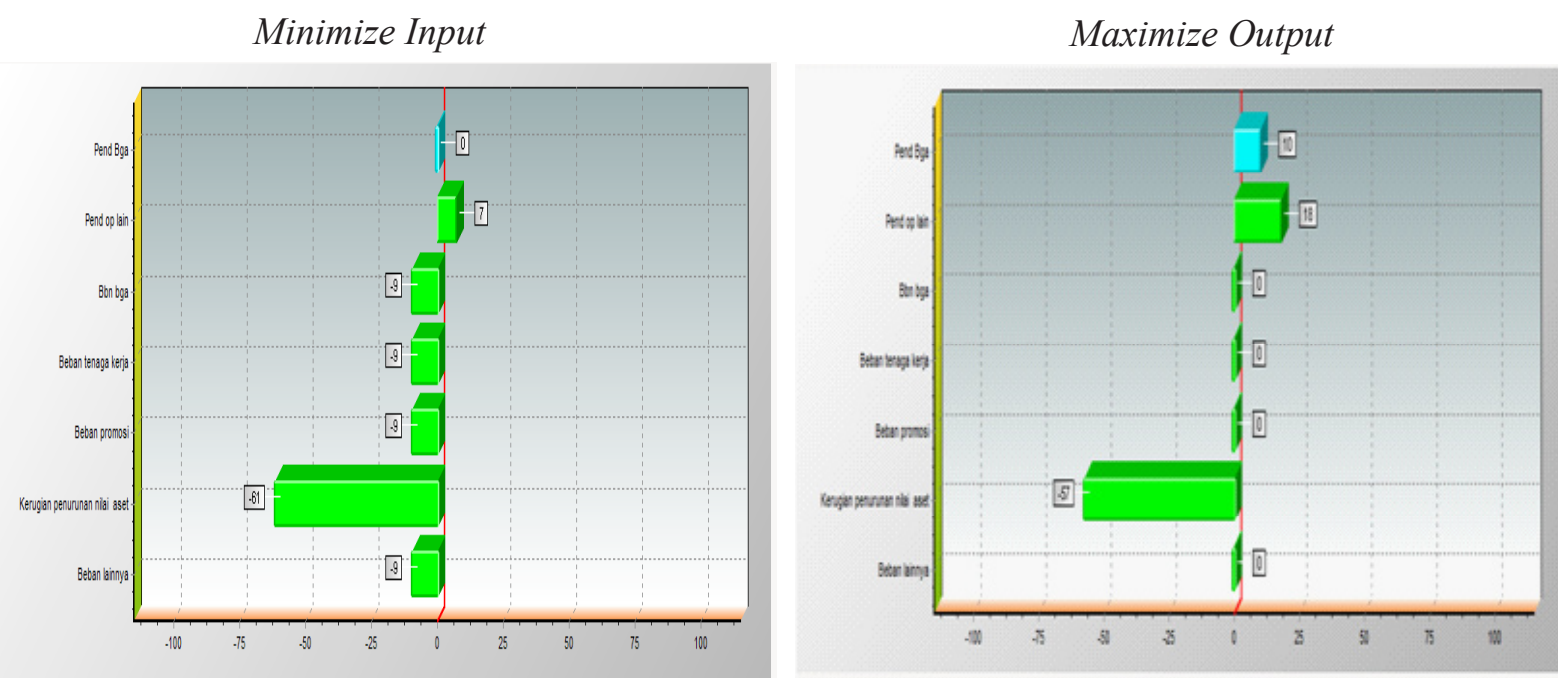

Gambar 6: Potential Improvement Bank BII

Bank Niaga dapat meningkatkan efisiensinya dengan cara menurunkan beban bunga, beban tenaga kerja, beban promosi, dan beban lainnya masing-masing sebesar 3\% dan kerugian penurunan nilai asset diturunkan sebesar $62 \%$.

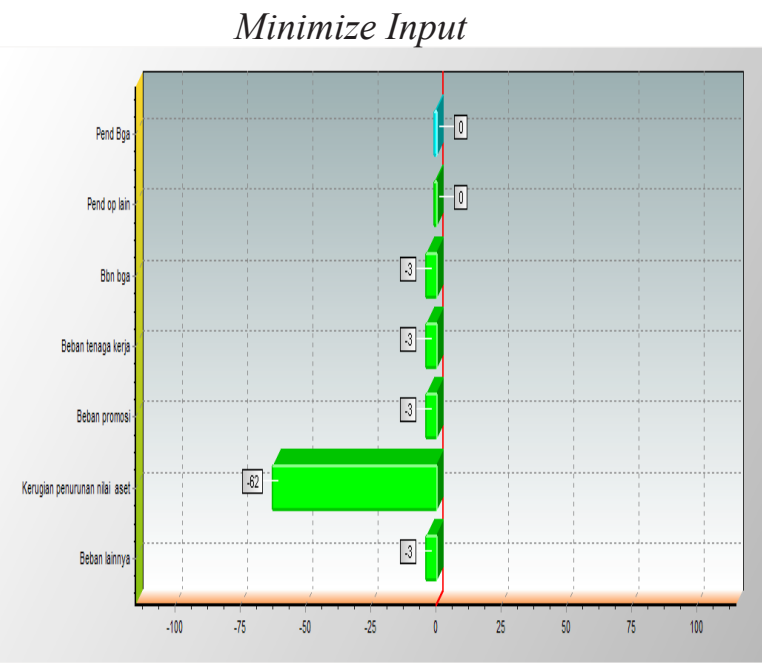

Gambar 7: Potential Improvement Bank Niaga-minimize input

Berdasarkan Gambar 7 Bank Niaga dapat meningkatkan efisiensinya dengan cara meningkatkan pendapatan bunga dan pendapatan operasional lain masing-masing 3\% dan menurunkan kerugian penurunan nilai asset $61 \%$.

\section{Kesimpulan, Keterbatasan dan Implikasi Hasil Penelitian}

bank terbesar di Indonesia dengan menggunakan DEA selama 2011-2014 dapat disimpulkan sebagai berikut:

1. DEA dapat menghasilkan skor efisiensi bank dan dapat memberikan informasi untuk bank

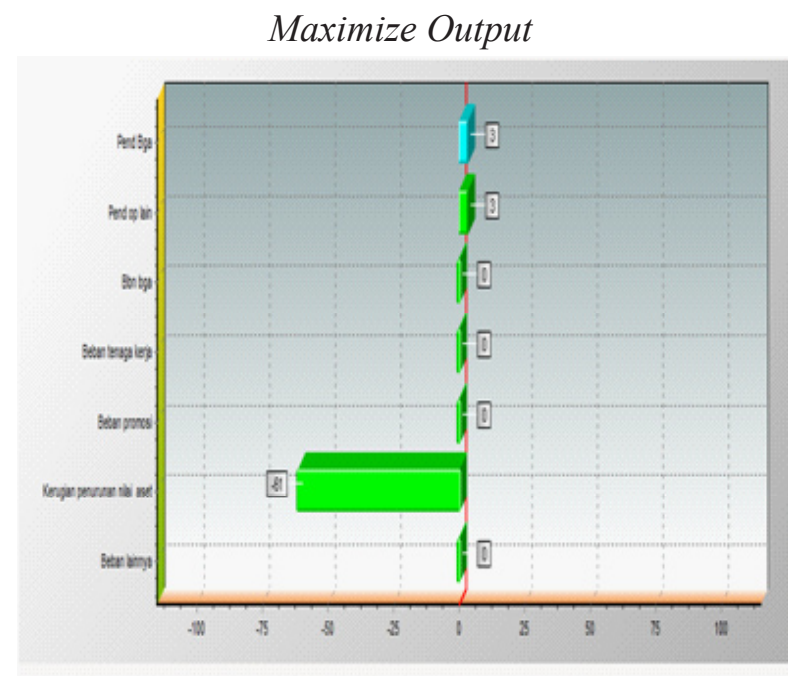

yang tidak efisien apa yang harus dilakukan agar dapat mencapai efisien.

2. Menggunakan production approach dengan kredit sebagai output ada 3 bank yang tidak efisien yaitu Bank BNI, Bank Danamon dan Bank Niaga. Dapat diartikan bahwa bank-bank tersebut kurang maksimal dalam ekspansi kreditnya.

3. Jika digunakan production approach 
dengan dana sebagai output bank yang tidak efisien hanya Bank Danamon. Berarti Bank Danamon kurang maksimal dalam ekspansi dana masyarakat.

4. Dengan menggunakan production approach dan sebagai outputnya adalah kredit dan dana juga hanya Bank Danamon yang tidak efisien. Berarti Bank Danamon kurang maksimal dalam ekspansi kredit dan dana masyarakat.

5. Khusus penggunaan intermediation approach hampir semua Bank tidak efisien kecuali BCA dan BTN. Berdasarkan hasil tersebut dapat diartikan bahwa peran ke-8 bank tersebut sebagai lembaga intermediasi kurang maksimal, kecuali Bank BCA dan BTN.

6. Bila digunakan revenue approach hanya Bank BNI yang tidak efisien, dapat diartikan bahwa dengan sumber daya yang ada Bank BNI belum maksimal dalam menghasilkan pendapatan.

7. Apabila digunakan profit approach selama periode tersebut ada 4 bank yang tidak efisien yaitu Bank BII, Bank BNI, Bank Niaga dan Bank Permata berarti ke-4 bank tersebut kurang maksimal dalam menghasilkan laba.

Implikasi hasil penelitian ini adalah bahwa model penilaian efisiensi dengan menggunakan DEA dapat diterapkan pada institusi keuangan yang sesuai. Penelitian ini hanya menguji 10 bank besar di Indonesia. Penelitian mendatang dapat melakukan pengujian/penilaian untuk berbagai jenis bank, baik bank umum, bank syariah, mapun bank pembangunan daerah. Riset juga dapat dilakukan dengan melakukan penilaian berdasarkan kelompok kepemilikan bank, swasta, asing, pemerintah.

\section{Daftar Pustaka}

Avkiran, Necmi., (1999), "Decomposing The Technical Efficiency of Trading Banks in The Dereguleted Period", Paper, The University of Queensland, Hospitality, Tourism, and Property Management, Australia.

Casu, Barbara, Philip Molyneux, (2000), “A Comparative Study of Efficiency in European Banking", Paper, University of Wales,
Bangor, UK.

Charnes, Abraham, William Cooper, Arie Y. Lewin, Lawrence M. Seiford, (2001), Data Envelopment Analysis, Theory, Methodology and Applications, Kluwer Academic Publishers, Boston, London, sixth printing.

Golany B. and Storbeck J.E., (1999), "A Data

Envelopment Analysis of The Operational Efficiency of Bank Branches", Interfaces 29, pp 14 - 26, copyright @ 1999, Insitute for Operation Research and the Management Sciences.

Hadad, Muliaman D, Wimboh Santoso dan Ita Rulina, (2003), "Indikator Kepailitan di Indonesia: An Additional Early Warning Tools Pada Stabilitas Sistem Keuangan", Makalah.

Hadad, Muliaman D, Wimboh Santoso, Dhaniel Ilyas, Eugenia Mardanugraha, (2003), "Analisis Efisiensi Industri Perbankan Indonesia: Penggunaan Metode Nonparametrik Data Envelopment Analysis (DEA)", Makalah.

Hadad, Muliaman D, Wimboh Santoso, Eugenia

Mardanugraha, Dhaniel Ilyas, (2003),

"Pendekatan Parametrik Untuk Efisiensi Perbankan Indonesia", Makalah.

Kumbhakar, Subal C., C.A. Knox Lovel, (2000), Stochastic Frontier Analysis, Cambridge University Press.

Laeven, Luc, (1999), "Risk and Efficiency in East Asian Banks", Makalah, The World Bank.

Madhanagopal R, R. Chandrasekaran, Global Economic Crisis and Productivity Changes of Banks in India: A DEA-MPI Analysis, International Journal of Data Envelopment Analysis and Operations Research. 2014, 1(3), 40-48

Mulyadi,(2006),'Penilaian Efisiensi dan Prediksi Kegagalan Bank dengan Metode Data Envelopment Analysis Studi Komparasi antar Bank di Indonesia". Disertasi, Universitas Persada Indonesia-YAI.

Nugroho, Sahid Susilo, (1995), "Analisis DEA dan Pengukuran Efisiensi Merek", Kelola, No. 8/IV.

Oral, Muhittin, Ossama Kettani, Reha Yolalan, 
(1992), “An Empirical Study on Analyzing the Productivity of Bank Branhces", IIE Transaction, Volume 24, Number 5, November

Saha, Asish, Ravisankar, (2000), "Rating of Indian Commercial Banks:A DEA approach", European Journal of Operational Research, 124, 187-203.

Santoso, Wimboh, (2005), "The Determinants of Problem Banks in Indonesia (An Empirical Study)", Makalah, JEL classification : G21; G 28 .

Sathye,Milind,(2001), "X-efficiencyinAustralian Banking: An Empirical Investigation", Journal of Banking \& Finance, 25, 613-630.

Seiford,L.M., (1994), A Data Envelopment Analysis Bibliography (1978-1992) in A Charnes, W.W. Cooper, A.Y. Lewin, and L. Sheiford, Data Envelopment Anaysis: Theory, Methodology and Apllications, Kluwer Academic Publishers, Boston.

Sengupta, Jati K., (2000), Dynamic and Stochastic Efficiency Analysis, Economics of Data Envelopment Analysis, World Scientific, Singapore.

Siswadi, Erwinta dan Wilson Arafat, (2004), "Mengukur Efisiensi Relatif Kantor Cabang Bank dengan Menggunakan Metode Data Envelopment Analysis", Usahawan, No. 01.

Siswadi, Erwinta, (2005), Aplikasi Data Envelopment Analysis (DEA), Bahan Worshop Sistem Pengukuran Kinerja Cabang Perusahaan dengan Pendekatan DEA, Lembaga Management Fakultas Ekonomi Universitas Indonesia.

Sya'dullah,Makmun,(2002),"MengukurEfisiensi Bank Pemerintah", Majalah Pengembangan Perbankan, Januari - Februari, No. 93, hal $35-42$.

Soteriou, Andreas C. and Stavrinides Yiannos, (1997), “An Internal Customer Service Quality Data Envelopment Analysis Model for Bank Branches", International Journal of Operations \& Production Management, Vol 17 No 8, pp 780-789.

Soteriou, Andreas and Zenios Stavros A., (1997), "Efficiency, Profitability, and Quality of
Banking Services", Working Paper, The Wharton Financial Institution Center, University of Pennsylvania. 